\title{
Dementia as a Public Health Priority
}

\author{
Sapkota $\mathbf{N}^{1}$, Subedi $\mathbf{S}^{2}$ \\ 1. Additional Professor, Department of Psychiatry, BPKIHS, Dharan, Nepal \& President, Alzheimer's \\ and Related Dementia Society Nepal 2. Associate Professor, Depatment Of Psychiatry, UCMS, \\ Bhairahawa, Nepal
}

E-mail *Corresponding author $: \underline{\text { sapkotanidesh@gmail.com }}$

\section{BACKGROUND}

The elderly population is substantially increasing not only in the high income countries but also in the low and middle income countries(LMICs) like Nepal in the past decade. As the world is graying, the chronic medical and neurological disease like dementia is expected to increase with elderly population growth. Dementia currently affects approximately 50 million people worldwide (or roughly $5 \%$ of the world's older population), a figure that is projected to increase to 82 million in 2030 and 152 million by 2050 . Recent reviews ${ }^{1}$ estimate that, globally, nearly 9.9 million people develop dementia each year; this figure translates into one new case every three seconds. Nearly $60 \%$ of people with dementia currently live in lowand middle-income countries and most new cases $(71 \%)$ are expected to occur in those countries. Dementia is the seventh leading cause of death globally and a major cause of disability and dependency among older people worldwide, which not only impacts individuals who have dementia but also their care takers, families, communities and societies. There is limited knowledge among health care providers regarding dementia and societal views regarding memory issues as normal consequences of ageing process specially in developing countries.

Greater awareness and understanding of dementia is important to challenge the myths and misconceptions that surround the condition. Dementia doesn't just affects individuals; it changes and affects the life of family members or the care takers. It has major burden for the family and leads financial implication. It is a costly condition in its social, economic and health dimensions. WHO report ${ }^{2}$ on dementia published in 2014 highlights the serious consequences of dementia in low and middle income countries and offers important statistics and key message for the policy makers. ${ }^{2}$

World Alzheimer Report 2019: Attitudes to dementia $^{3}$ : The report reveals the results of the largest attitudes to dementia survey ever undertaken, with almost 70,000 people across 155 countries and territories completing the survey. It spans four demographic groups: people living with dementia, their care takers, healthcare practitioners and the general public. Analysis of the study, which collected responses from, was carried out by the London School of Economics and Political Science (LSE).

Some of the key findings of the report include:

- Almost $80 \%$ of the general public are concerned about developing dementia at some point and $\mathbf{1}$ in $\mathbf{4}$ people think that there is nothing we can do to prevent dementia

- About $35 \%$ of carers across the world said that they have hidden the diagnosis of dementia of a family member

- Over $\mathbf{5 0 \%}$ of carers globally say their health has suffered as a result of their caring responsibilities even whilst expressing positive sentiments about their role.

- Almost $\mathbf{6 2} \%$ of healthcare providers worldwide think that dementia is part of normal ageing

- About $40 \%$ of the general public think doctors and nurses ignore people with dementia

- About 63\% in South East Asia, said their dementia symptoms were joked about by others

- About $45 \%$ of people living in South-East Asia and $48 \%$ of healthcare practitioners in the 
region feel that people with dementia are dangerous.

- About $60 \%$ of people felt it was important to remove responsibilities of people living with dementia

\section{Demographic Dynamics of Elderly Nepalese 4,5} Elderly population in Nepal (age 60 years and above) is growing more than the general population. In 2001, there were 1.5 million older people in Nepal; this population has increased in 2011 to 2.7 million, accounting for $9 \%$ of Nepal's population. The 2011 census has revealed that the rate of general population growth is $2.1 \%$ and $3.4 \%$ in the elderly. If the growth continues to increase at this rate, the population of senior citizens would become $3,779,772$ by 2021 . In the next ten years, over 1.3 million elderly populations will be added. ${ }^{3}$ This would not only have great social implications but also on the health sector. This shift in the elderly cohort directly reflects to the increment in the number of dementia cases in the community as old age is an important risk factor for Dementia. In Nepal except hospital based study we don't have prevalence data but based on elderly population and at least 5 percent prevalence of Dementia among 2.7 million elderly population in the country as per 2011 National census it can be estimated that there can be at least 135,000 suffering from dementia. The hospital based data conducted as a thesis work " Prevalence of dementia in old age patients attending Psychiatric clinic in a tertiary care centre over a period of one year" reveals $11.4 \%$ of them had dementia. ${ }^{4}$

\section{Status of Dementia care and assessment in} Nepal 6:

There is least priority from the policy makers for non communicable diseases in low and middle income countries and Nepal isn't an exceptional country. Nepal government has provided $50 \%$ financial concessions in investigations and hospital charges for the geriatric population however they needed to produce citizenship certificate to avail such incentives. The government also provides financial incentives of worth Rs 100,000 if patient meets the criteria for Alzheimer's dementia. This policy in itself is good to start with but it has limited to one type of dementia whereas in practice many patients may have mixed dementia or other related problems. There are no nursing homes specially designed for people with dementia or cognitive impairment however there are care homes run by the private sectors. They lack training and expertise to deal patients with dementia who has behavioural problems. The proper dementia assessment is way far behind with respect to the developed country however cognitive impairment screening is done in Medical college hospitals and some corporate hospitals including zonal hospitals.

\section{Problem in Developing country 7}

Memory issues and its impact in quality of life isn't regarded as a serious problem in LMICs. It is believed as age driven phenomenon and inevitable. LMICs have their own problem like infectious disease control burden along with other common non communicable diseases. There is often a lack of awareness and understanding of dementia, resulting in stigmatization and barriers to diagnosis and care. Evidence suggests that up to $90 \%$ of people with dementia in LMICs do not receive a diagnosis, preventing them from accessing services and receiving support.

Dementia is not yet a national priority in most countries including Nepal. This will led to a lack of systematic monitoring and evaluation of dementia; only about $15 \%$ of countries that are members to Alzheimer's disease International(ADI) currently have National Dementia plan to address dementia. Nepal also has submitted its National dementia plan through Alzheimer's and Related Dementia Society Nepal but hasn't received any focus and priority from the concerned authority.

\section{WHO Initiatives ${ }^{8}$ :}

The Seventieth World Health Assembly endorsed the global action plan on the public health response to dementia 2017-2025 in May 2017; thereby committing to reaching global targets across seven key action areas:

Action area 1: Dementia as a public health priority

Action area 2: Dementia awareness and friendliness

Action area 3: Dementia risk reduction 
Action area 4: Dementia diagnosis, treatment, care and support

Action area 5: Support for dementia carers Action area 6: Information systems for dementia Action area 7: Dementia research and innovation

Along with the identifiable action areas it also focused on the development of national strategies and plans. The global action plan emphasizes the need to integrate health and social care approaches and align actions with ongoing strategic developments in mental health, non-communicable diseases (NCDs) and ageing.

\section{Why Dementia should be a public health priority?}

The world's population is ageing hence the world is graying so as the elderly cohort dynamics too in Nepal. The life expectancy at birth of Nepalese population as of by 2017 is 70.16. ${ }^{9}$ Age is the strongest known risk factor for the onset of dementia however $9 \%$ of all cases of dementia are early onset that occurs in young $(<65$ years of age). Some research has shown a relationship between the development of cognitive impairment and lifestyle-related risk factors that are shared with other noncommunicable diseases. These Dementia accounts for $11.9 \%$ of the years lived with disability due to a non-communicable disease. ${ }^{10}$ Most of the developed countries and many of the developing countries already have National dementia plan or they have started developing it. So it is expected that $75 \%$ of countries will have developed or updated national policies, strategies, plans or frameworks for dementia, either stand-alone or integrated into other policies/plans, by 2025. Dementia leads to increased costs for governments, communities, families and individuals, and to loss in productivity for economies. Dementia has been emerging as the billions and trillions dollars disease in terms of holistic management. In 2015, dementia costs were estimated at US\$ 818 billion, equivalent to $1.1 \%$ of global gross domestic product, ranging from $0.2 \%$ for LMICs to $1.4 \%$ for high income countries which would further increase to US \$ 2 trillion by $2030 .{ }^{1.11} \mathrm{It}$ isn't possible for developing country like Nepal to spend $0.2 \%$ of its GDP for one disease entity where its health budget is less than $4 \%$ of its annual fiscal year budget. Nepal has entered to the federal system so there can be other challenges regarding health sector. It is pertinent for the federal system government to anticipate the upcoming health issues to address it appropriately and efficiently hence people living with dementia should be given high priority including their primary care takers or else this world is graying and dementia has been emerging as an neurodegenerative epidemic.

\section{REFERENCES:}

1. The epidemiology and impact of dementia: current state and future trends. Geneva: World Health Organization; 2015

2. http://www.who.int/mental_health/publications/demen tia_report_2014

3. World Alzheimer Report 2019: Attitudes to dementia. London: Alzheimer's Disease International.

4. Central Bureau of Statistics, National Population and Housing census 2011(National report). Government of Nepal, National Planning commissions.

5. Nepal, S E Sapkota, N. (2018). Prevalence of Dementia among Elderly Patients attending Psychiatry OPD of Tertiary Care Hospital and its Association with Socio Demographic Variables. Journal of Psychiatrists' Association of Nepal. 6. 12. 10.3126/jpan.v6i1.21766.

6. Sapkota, N. (2017). The world is graying: Dementia is an alarming issue. Health Renaissance, 13(3), 1-6. https://doi.org/10.3126/hren.v13i3.17921.

7. World Alzheimer Report 2012, Overcoming the Stigma of dementia. http://www.alz.co.uk/research/worldreport-2012.

8. http://www.who.int/mental_health/neurology/dementia laction_plan_2017_2 025/en/

9. United Nations Population Division. World Population Prospects: 2019 Revision or derived from male and female life expectancy at birth.

10. Prince M, Albanese E, Guerchet M, Prina M. World Alzheimer Report 2014. Dementia and risk reduction: an analysis of protective and modifiable risk factors. London: Alzheimer's Disease International; 2014 (http://www.alz.co.uk/research/WorldAlzheimerReport 2014).

11. Prince M, Wimo A, Guerchet M, Ali GC, Wu Yutzu, Prina M. World Alzheimer Report 2015. The global impact of dementia: an analysis of prevalence, incidence, cost and trends. London: Alzheimer's Disease International; 2015. 